\title{
GAMBARAN PERSEPSI REMAJA PUTRI TENTANG KEKERASAN DALAM PACARAN DI SMK NEGERI 01 NANGGULAN KULONPROGO
}

\author{
Nuuva Yusuf ${ }^{1}$, Dwi Riyan Ariestantia ${ }^{2}$, Ryzky Diah Anggraini ${ }^{3}$ \\ ${ }_{1,2,3}$ Akademi Kebidanan Mutiara Mahakam \\ Email : nuuvayusuf@gmail.com
}

\begin{abstract}
Dating violence is often found as community problem which is part of intimate partner violence but many adolescents do not understand and aware themselves as victims of violence. The aim of the study was to describe the perceptions of young women about dating violence on female students at dating violence of students of vocational school SMK Negeri 1Nanggulan KulonProgo using descriptive descriptive method with a cross sectional approach. Data analysis using Chi square with an error rate of 0.05 . The results of this study on the perceptions of adolescents about violence on female students of SMK Negeri 1 Nanggulan were 89 students (62.2\%). Poor perception of 54 female students (37.8\%). Adolescents 'perceptions of violence both indicate that respondents have an understanding that violence is wrong and unnatural in a dating relationship and respondents' understanding is good about the form of violence
\end{abstract}

Keywords : perception, violence, dating violence

\section{PENDAHULUAN}

Pacaran merupakan proses perkenalan antara dua insan manusia yang biasanya berada dalam rangkaian tahap pencarian kecocokan menuju kehidupan berkeluarga yang dikenal dengan pernikahan. Pada kenyataannya, penerapan proses tersebut masih sangat jauh dari tujuan yang sebenarnya. Manusia yang belum cukup umur dan masih jauh dari kesiapan memenuhi persyaratan menuju pernikahan telah dengan nyata membiasakan tradisi yang semestinya tidak mereka lakukan khususnya pada remaja (Santrock, 2011).

Hubungan ini memiliki efek terhadap kehidupan remaja baik positif maupun negatif tergantung yang menjalaninya. Pacaran dapat memberikan efek negatif jika dalam pacaran muncul perilaku seksual dan kekerasan (BKKBN, 2013).

Remaja dalam perkembangannya cenderung sulit dalam pengendalian diri sehingga rentan mengalami ataupun melakukan kekerasan dalam pacaran (KDP) atau disebut Dating Violence. Dating Violence adalah segala bentuk tindakan kekerasan emosional, psikologi, fisik maupun seksual yang dialami remaja dalam berpacaran. (Payne, 2013).

Angka prevalensi kekerasan terhadap perempuan di Asia Tenggara sebanyak 37,7\%, Afrika 36,6\% dan bahkan negara Amerika Serikat yang merupakan negara sangat maju memiliki prevalensi 29,8\%. Di Afrika Selatan $42 \%$ usia 12-23 tahun dilaporkan mengalami kekerasan fisik dalam pacaran (WHO, 2013). Dalam hal ini, kenyataannya bahwa perempuan merupakan pihak yang paling rentan terhadap adanya tindakan kekerasan karena mereka menjadi sasaran bagi laki-laki.

Di Indonesia, 216.156 kasus kekerasan terhadap perempuan yang dilaporkan dan ditangani selama tahun 2012 salah satunya sebanyak 1.085 kasus kekerasan dalam pacaran (Komnas Perempuan, 2012). Sedangkan pada tahun 2013 jumlah kasus KDP meningkat menjadi 2.507 kasus dari total 
11.719 kasus diranah personal (Komnas Perempuan, 2013).

Data konseling Rifka Annisa untuk KDP pada tahun 2009-2012 sebanyak 139 kasus (BAPPEDA DIY, 2013). Pada kasus KDP, sebagian besar korban yang teraniaya secara fisik dan psikis adalah perempuan. Namun, seorang korban kekerasaaan akibat KDP sering tidak melakukan tindakan apapun dan menganggapnya sebagai sebuah petualangan atau hal yang biasa (Kementrian Negara Pemberdayaan Perempuan, 2008).

Berdasarkan penelitian Ayu (2012) tentang "Kekerasan Dalam Pacaran dan Kecerdasan Remaja Putri di Kabupaten 2 Purworejo" didapatkan hasil bentuk kekerasan yang dialami oleh remaja putri antara lain kekerasan fisik 30,38\%, kekerasan seksual $34,71 \%$, kekerasan emosional $17,5 \%$, dan kekerasan ekonomi $25,83 \%$.

Berdasarkan penelitian yang dilakukan oleh Pamela (2012) di dalam "Teen Dating Violence" yang dilakukan di Amerika melaporkan bahwa $35,6 \%$ mengalami pengendalian perilaku yang dilakukan oleh pasangan,

direndahkan oleh pasangan, dan $44,3 \%$ mengalami penghinaan.

Penyebab tingginya angka kekerasan dalam pacaran terjadi akibat banyaknya perempuan yang tidak paham bentuk kekerasan fisik maupun psikis dalam suatu hubungan. Membiarkan hubungan yang tidak sehat, bahkan sampai melakukan tindak kekerasan, dapat menimbulkan risiko atau dampak yang fatal (Hasan, 2013).

Kekerasan terhadap perempuan dalam hal ini adalah kekerasan dalam pacaran masih jarang dibicarakan secara terbuka dan seringkali dianggap tidak penting, karena data yang berkaitan dengan KDP juga sulit didapatkan. Tindakan kekerasan dalam pacaran sering ditemukan tetapi banyak para remaja yang belum memahami, sehingga terkadang tidak menyadari dirinya sebagai korban kekerasan (Arini, 2013).

Pemahaman seseorang terhadap suatu objek ini dapat diartikan sebagai persepsi sehingga muncul pengorganisasian dan penafsiran seseorang. Persepsi adalah proses seseorang memahami lingkungan, meliputi pengorganisasian dan penafsiran rangsang dalam suatu pengalaman psikologis (Hidayat, 2004).

Kekerasan memiliki dampak negatif terhadap pelaku maupun korban KDP. Korban KDP memiliki dampak seperti gangguan fisik, harga diri rendah, depresi hingga bunuh diri, serta kebiasaan yang tidak sehat seperti gangguan pola makan dan pola tidur, merokok, penggunaan alkohol dan NAPZA, seks bebas, hingga kehamilan tidak diinginkan dan penyakit menular seksual (WHO, 2012). Dampak kekerasan dalam pacaran juga menjadi sebuah kecenderungan untuk terjadi kekerasan dalam rumah tangga (Yayasan Pendidikan Kesehatan Perempuan, 2006).

Data fenomena KDP masih terbatas dan sedikit yang terungkap sedangkan dampak negatif generasi muda sangat besar. Hal ini menunjukkan bahwa KDP sulit diungkap oleh korban maupun masyarakat. WHO membuat langkah pencegahan KDP yang diinisiasikan dalam program life skills yang bertujuan untuk meningkatkan pengetahuan, sikap dan kebiasaan remaja maupun kelas berbasis pencegahan dalam pacaran seperti Safe Dates di USA (WHO, 2012). Berdasarkan hasil studi pendahuluan yang dilakukan pada tanggal 9 Mei 2014 di SMK Negeri 1 Nanggulan Kulon Progo pada 30 siswi kelas $\mathrm{X}, \quad$ didapatkan hasil penelitian bahwa dari 30 siswi, 1 siswi diantaranya pernah mengalami kekerasan fisik yang dilakukan oleh pacarnya, dengan sikap positif 6 siswi (20\%) yang menunjukkan bahwa siswi menerima atau mendukung kekerasan dalam pacaran, 
3 dan 24 siswi (80\%) bersikap negatif yang menunjukkan menolak kekerasan dalam pacaran. Dari 30 siswi 22 (73\%) memiliki persepsi baik tentang kekerasan, dan 8 siswi (27\%) berpersepsi kurang baik tentang kekerasan diantaranya menganggap bahwa kekerasan itu jika seseorang sudah mengalami luka atau memar yang parah.

Berkaitan dengan masalah tersebut peneliti tertarik untuk meneliti persepsi remaja tentang kekerasan dalam pacaran pada siswi di SMK Negeri 1 Nanggulan Kulon Progo tahun 2014.

Tujuan penelitian ini diketahuinya persepsi remaja tentang kekerasan dalam pacaran pada siswi di SMK Negeri 1 Nanggulan Kulon Progo tahun 2014.

\section{METODE PENELITIAN}

Penelitian ini merupakan jenis penelitian deskriptif observasional dengan desain cross sectional yang bertujuan untuk memberikan gambaran tentang persepsi remaja putri tentang kekerasan dalam pacaran di SMK Negeri 1 Kulonprogo Yogyakarta. Teknik sampel yang digunakan dalam penelitian ini adalah dengan Proportinate Random Sampling. Sampel dalam penelitian ini adalah seluruh siswi kelas X dan XI SMA Negeri 1 Nanggulan Kulon Progo. Sampel yang ditemukan sebanyak 143 siswi.

Dalam penelitian ini, menggunakan kuesioner sebagai alat untuk mengumpulkan data. Pembagian kuesioner akan dilakukan dengan alokasi waktu dari kepala sekolah dan peneliti. Seluruh responden akan dikumpulkan sesuai kelas masing-masing. Selanjutnya peneliti menjelaskan judul penelitian, tujuan dan manfaat dilakukannya penelitian ini dan peneliti membagikan lembar persetujuan (informed consent) menjadi responden kepada siswi yang bersedia dan sukarela menjadi responden dalam penelitian ini untuk diisi. Data yang diperoleh kemudian akan diolah dengan menggunakan SPSS versi 16.0.
Kuesioner dalam penelitian ini terdiri dari Persepsi remaja tentang kekerasan adalah penafsiran atau penilaian dalam menerima informasi dari seseorang sebagai stimulasi yang didapatkan responden dan mengorganisasi serta menginterpretasikan mengenai pemahaman yang diungkapkan responden setelah memperoleh informasi terkait bentuk-bentuk kekerasan dalam pacaran yang meliputi kekerasan fisik, kekerasan emotional, kekerasan seksual dan kekerasan ekonomi. Terdapat empat pilihan alternatif jawaban dalam setiap pernyataan kuesioner persepsi remaja tentang kekerasan dan sikap terhadap kekerasan dalam pacaran yaitu ada dalam skala Likert sangat setuju (SS), setuju (S), tidak setuju (TS), sangat tidak setuju (STS).

\section{HASIL DAN PEMBAHASAN}

Tabel 1. Distribusi Frekuensi Karakteristik Responden Berdasarkan Umur Siswi Di SMK Negeri 1 Nanggulan Kulon Progo

\begin{tabular}{lll}
\hline $\begin{array}{l}\text { Karakteristik } \\
\text { Responden }\end{array}$ & $\begin{array}{l}\text { Frekuensi } \\
(\text { F) }\end{array}$ & $\begin{array}{l}\text { Persesntase } \\
(\%)\end{array}$ \\
\hline Umur & & \\
15 tahun & 18 & $12,6 \%$ \\
16 tahun & 69 & $48,3 \%$ \\
17 tahun & 49 & $34,3 \%$ \\
18 tahun & 6 & $4,2 \%$ \\
19 tahun & 1 & $7 \%$ \\
Jumlah & 143 & $100 \%$ \\
\hline
\end{tabular}

Sumber : Data Primer 2014

Tabel 2. Distribusi Frekuensi Persepsi Remaja Tentang Kekerasan di SMK Negeri 1 Nanggulan Kulon Progo

\begin{tabular}{llll}
\hline No & Persepsi & $\begin{array}{l}\text { Frekuensi } \\
(\text { F) }\end{array}$ & $\begin{array}{l}\text { Persentase } \\
\text { (P) }\end{array}$ \\
\hline 1. & Baik & 89 & $62,2 \%$ \\
2. & Kurang baik & 54 & $37,8 \%$ \\
& Jumlah & 143 & $100 \%$ \\
\hline
\end{tabular}
Sumber : Data Primer 2014

\section{Persepsi Remaja Tentang Kekerasan}

Berdasarkan tabel 2. Persepsi remaja tentang kekerasan pada siswi di SMK Negeri 1 
Nanggulan sebanyak 89 siswi $(62,2 \%)$ mempunyai persepsi baik, dan 54 siswi $(37,8 \%)$ mempunyai persepsi kurang baik. Dari hasil tersebut persepsi responden baik tentang bentuk kekerasan. Pada kuesioner persepsi remaja tentang kekerasan komponen yang diukur meliputi bentuk-bentuk kekerasan yaitu kekerasan fisik, kekerasan seksual, kekerasan emotional dan kekerasan ekonomi. Hasil penelitian ini didukung oleh penelitian yang dilakukan Evlyn (2007) menunjukkan bahwa persepsi yang baik terhadap seks sebanyak 96,7\%. Bennet (Luanaigh, 2008), mengemukakan bahwa ketika seorang individu melihat sebuah target dan berusaha untuk menginterpretasikan apa yang ia lihat, interpretasi itu sangat dipengaruhi oleh berbagai karakteristik pribadi dari pembuat persepsi tersebut, seperti sikap, kepribadian, motif, minat, pengalaman-pengalaman masa lalu dan pengharapan.

Responden yang memiliki persepsi baik dengan kekerasan yang dipersepsikannya, maka responden akan menolak terhadap kekerasan dalam pacaran. Persepsi memiliki peranan penting dalam berperilaku seseorang. Sebagai pembentukan sikap terhadap obyek atau peristiwa yang berarti akan berpengaruh terhadap perilaku yang lebih terarah.

Pada kuesioner persepsi remaja tentang kekerasan emotional 68 siswi $(47,6 \%)$ menganggap tidak wajar pacarnya merasa cemburu yang berlebihan dan 75 siswi $(52,4 \%)$ mengganggap wajar pacarnya cemburu berlebihan. Sebanyak 89 siswi $(62,3 \%)$ merasa tidak wajar jika pacarnya membatasi pergaulan dengan orang tua dan teman-teman dan 54 siswi $(37,8 \%)$ merasa wajar jika pacarnya membatasi pergaulan dengan orang tua dan teman-teman. Hal ini menunjukkan bahwa responden masih menganggap hal wajar dan mempunyai persepsi yang kurang jika dilihat dari jawaban pada item kekerasan emosional.

Persepsi remaja tentang kekerasan ekonomi 110 siswi (77\%) menyatakan tidak wajar jika pasangan menyuruh untuk mentraktir makan teman-temannya dan 34 siswi $(23 \%)$ menyatakan wajar jika pasangan menyuruh mentraktir makan teman-temannya. Sebanyak 134 siswi $(93,7 \%)$ setuju pada pernyataan pasangan yang baik harus bertanggung jawab mengganti barang yang dihilangkan. Menurut Prayanti (2011) Kekerasan ekonomi adalah tindakan yang bertujuan menekan korban secara ekonomi atau keuangan. Seperti meminta pasangan membayarkan makanan, pakaian, pulsa dan kebutuhan lainnya (Arini, 2013).

Persepsi remaja tentang kekerasan fisik sebanyak 89 siswi $(62,3 \%)$ menganggap setuju kekerasan adalah ketika dirinya sudah mendapatkan luka atau memar, dan 54 siswi $(37,7 \%)$ tidak setuju kekerasan ditandai dengan mendapatkan luka atau memar. Sebanyak 23 siswi $(16,1 \%)$ menganggap wajar ketika pacar marah kemudian melemparkan benda tajam ke arah pasangannya.

Pada item kekerasan seksual 11 siswi $(7,7 \%)$ tidak tahu bhwa memaksa untuk mencium pasangan adalah termasuk kekerasan dan 132 siswi (92,3\%) mengetahui bahwa meminta paksa mencium pasangan adalah bentuk kekerasan. Sebanyak 137 siswi $(95,8 \%)$ menganggap hal yang tidak wajar saat pacar memaksa untuk melakukan hubungan seksual dan 6 siswi (4,2\%) menganggap wajar pacar memaksa untuk melakukan hubungan seksual. Persepsi mereka yang kurang baik akan meningkatkan kasus kekerasan dalam pacaran dan berdampak buruk bagi korban khususnya dampak kesehatan reproduksi. Menurut Syamsul Hadi dan Aminah (2002) dampak yang akan timbul pertama, bila terjadi kehamilan tak dikehendaki dan pacar meninggalkan kita. Ada dua kemungkinan: melanjutkan kehamilan atau aborsi. Bila aborsi, ia harus siap menanggung resikoresiko, seperti perdarahan, infeksi dan bahkan kematian. Seringkali walaupun pacar tidak meninggalkan, namun perempuan dipaksa untuk aborsi. Kedua, bila terjadi hubungan 
seksual dalam pacaran, perempuan akan rentan terkena penyakit menular seksual (PMS) seperti gonorhea, syphilis, kutu, herpes dan termasuk juga HIV/AIDS.

\section{SIMPULAN DAN SARAN}

A. Simpulan

Persepsi remaja tentang kekerasan pada siswi SMK Negeri 1 Nanggulan Kulon Progo adalah baik sebanyak 89 siswi $(62,2 \%)$, hal ini dapat disimpulkan bahwa persepsi remaja tentang kekerasan baik menunjukkan bahwa responden memiliki pemahaman bahwa kekerasan hal yang salah dan tidak wajar dalam suatu hubungan pacaran dan pemahaman responden baik tentang bentuk kekerasan.

B. Saran

Berdasarkan pembahasan dan kesimpulan dalam penelitian ini, maka saran yang dapat diberikan adalah sebagai berikut :

1. Bagi Kepala Sekolah dan Guru SMK Negeri 1 Nanggulan Kulon Progo. Hasil penelitian ini dapat menjadi masukan untuk guru di SMK Negeri 1 Nanggulan Kulon Progo yaitu khusunya guru BK untuk lebih memberikan informasi terkait kesehatan reproduksi remaja khususnya kekerasan dalam pacaran yang dapat mengakibatkan kesehatan reproduksi remaja dalam hal fisik dan psikologi remaja tersebut dengan menambah di sela-sela jam pelajaran atau waktu khusus dan waktu bimbingan siswa dengan bekerjasama dengan Puskesmas setempat dan tenaga kesehatan lainnya dan dengan menggerakkan kegiatan PIKRR di SMK Negeri 1 Nanggulan

2. Bagi siswi SMK Negeri 1 Nanggulan Kulon Progo. Hasil penelitian ini dapat memberikan informasi dan menjadi acuan, sehingga dapat terhindar dari bentuk kekerasan dalam pacaran dan bersikap tepat terhadap kekerasan dalam pacaran.

3. Bagi peneliti selanjutnya yaitu hendaknya dalam melanjutkan penelitian lebih mengungkap faktor yang lain yang mempengaruhi sikap terhadap kekerasan dalam pacaran selain faktor persepsi remaja dengan memperbanyak variabel dan menggunakan metode yang lebih baik untuk menggali informasi secara mendalam tentang sikap terhadap kekerasan dalam pacaran dengan metode kualitatif sehingga dapat memperkuat penelitian.

\section{DAFTAR PUSTAKA}

Arini. (2013) Mereka Bicara Tentang Kespro \& KDP. Jakarta : Rahima

Ayu, Suci M. (2012) Kekerasan Dalam Pacaran dan Kecemasan Remaja Putri di Kabupaten Purworejo [internet]. Yogyakarta : Fakultas Kesehatan Masyarakat Universitas Ahmad Dahlan. Tersedia dalam <http://portalgaruda.org > [diakses tanggal 2 Februari 2014]

BAPPEDA DIY. (2013) Revitalisasi Peran Keluarga dalam Rangka Peningkatan Kesejahteraan Sosial Anak. Tersedia dalam http://bappeda.jogjaprov.go.id [di akses pada 15 Mei 2014]

Hadi, Syamsul dan Aminah, Siti. (200) Kekerasan Di Balik Cinta. Yogyakarta : Rifka Annisa

Hasan, Nur (2013) Kekerasan Dalam Pacaran. [intenet] Jakarta : Koran Media Indonesia. Tersedia dalam <https://www.jurnalperempuan.org> [ diakses 31 jan 2013 ]

Hidayat, Dkk. (2009) Wajah Kakerasan. Yogyakarta : Rifka Annisa 
Komisi Nasional Perempuan (2013). Laporan Hasil Kerja Komisi Nasional Anti Kekerasan Terhadap Perempuan Tahun (Catahu) 2013. Tersedia dalam http://komnasperempuan.or.id [di akses pada 13 Mei 2014]

Pamela. 2012) Teen Datin Violence [internet]. Tersedia dalam $<$ http://soroptimist.org> [di akses pada 15 Mei 2014]

Payne ,K. L.,Ward, T., Miller. A., \&Vasquez, K. (2013) Teen Dating Violence: A Resouce and Prevention Toolkit dalam Alverno College Research Center For Women And Girls. Tersedia dalam http://alverno.edu.pdf [di akses pada 24 Januari 2014]
Santrock, J.W., (2011) Life Span Development : Perkembangan Masa Hidup Edisi ke-13 Jilid 1. Jakarta : Erlangga

WHO. (2012) Understanding And Addressing Violence Against Women: Intimate Partner Violence. Tersedia dalam http:// who.int [di akses pada 26 Januari 2014]

WHO. (2013) Preventing Violence: Evaluating Outcomes of Parenting Programmes. Tersedia dalam http:// who.int [di akses pada 25 Januari 2014]

Yayasan Pendidikan Kesehatan Perempuan. (2006) Modul Kesehatan Reproduksi Kekerasan Terhadap Perempuan dan Anak. Jakarta 